\title{
The chemical brain hypothesis for the origin of nervous systems
}

\author{
Gáspár Jékely \\ Living Systems Institute, University of Exeter, Stocker road, Exeter, UK \\ g.jekely@exeter.ac.uk
}

\begin{abstract}
In nervous systems, there are two modes of transmission for the propagation of activity between cells. Synaptic transmission relies on close contact at chemical or electrical synapses while volume transmission is mediated by diffusible chemical signals and does not require direct contact. It is possible to wire complex neuronal networks by both chemical and synaptic transmission. Both types of networks are ubiquitous in nervous systems, leading to the question which of the two appeared first in evolution. This paper explores a scenario where chemically organised cellular networks appeared before synapses in evolution; a possibility supported by the presence of complex peptidergic signalling in all animals except sponges. Small peptides are ideally suited to link up cells into chemical networks. They have unlimited diversity, high diffusivity and high copy numbers derived from repetitive precursors. But chemical signalling is diffusion limited and becomes inefficient in larger bodies. To overcome this, peptidergic cells may have developed projections and formed synaptically connected networks tiling body surfaces and displaying synchronised activity with pulsatile peptide release. The advent of circulatory systems and neurohemal organs further reduced the constraint imposed on chemical signalling by diffusion. This could have contributed to the explosive radiation of peptidergic signalling systems in stem bilaterians. Neurosecretory centres in extant nervous systems are still predominantly chemically wired and coexist with the synaptic brain.
\end{abstract}

Keywords: nervous system evolution, neuropeptide, paracrine signalling, placozoa, sponge, ctenophore, cnidaria

\section{Introduction}

Many theories have been put forward to explain nervous system evolution. The different theories often focus on the evolution of some salient aspects of the brain. These include the evolution of electrical conduction [1], the origin of spiking and voltage-gated channels [2,3], the diversification of neuronal cell types [4], the patterning of the nervous system along the main axes of the body [5,6], the development of neuronal elongations and synaptic circuits [7], the origin of sensory capacities $[8,9]$ or the internal coordination of muscles [10]. These various theories are often complementary and attempt to give an account of nervous system origins from different angles [11].

Here, I approach the question by asking how the first proto-neurons organised into cellular networks with the rapid (non-developmental) propagation of excitation. I propose a detailed, testable hypothesis that I refer to as the chemical brain hypothesis for nervous system origins. The theory suggests that the first cellular networks involved in sensing, reacting and coordination of whole-body activity were organised by paracrine signalling. As signalling molecules, I will discuss the potential early origin and function of secreted neuropeptide-like molecules (in short, neuropeptides). 
Neuropeptides are abundant, diverse secreted intercellular signalling molecules, which are near-ubiquitous in nervous systems. The active signalling peptides are produced in the Golgi from larger propeptides through successive steps of proteolytic cleavages and further chemical modifications. Cleavages generally occur at di- or monobasic cleavage sites (e.g. KR) by prohormone convertases. The cleaved peptides can be further modified, most often by C-terminal $\alpha$-amidation during which the bifunctional peptidylglycine $\alpha$-amidating monooxygenase (PAM) enzyme converts a C-terminal glycine into an amide [12]. Mature peptides travel in secretory vesicles called dense-core vesicles and are released at synapses or at non-specialised release sites along neurites. Release is regulated by intracellular CAMP and calcium levels [13-15]. The machineries for the acidification and release of dense-core vesicles and synaptic vesicles have many shared but also unique components [16-18]. Secreted peptides diffuse as paracrine signalling molecules or are transported by the bloodstream if the release occurs in neurohaemal organs (e.g. vertebrate pituitary). Neuropeptides act through cell surface receptors, most commonly G-protein coupled receptors (GPCRs).

The general idea that volume transmission may have evolved before synaptic transmission has been proposed by Grundfest, Horridge and others (reviewed in refs. [19,20]). In the first section, I define the chemical brain hypothesis and discuss the possibilities and constraints of peptidergic signalling to organise cellular networks. In section two, I discuss cellular transition scenarios for nervous system origins, in light of the hypothesis. Finally, I discuss some predictions of the hypothesis and how it could be tested.

\section{The chemical brain hypothesis}

This section starts by introducing the main postulates of the chemical brain hypothesis. I will then explore why peptides became the most abundant intracellular signalling molecules in animal nervous systems. I also discuss how peptidergic signalling can wire complex cellular networks.

\section{A. Formulation of the hypothesis}

The chemical brain hypothesis posits that elementary nervous systems first evolved as chemically connected networks of excitable cells (Figure 1). In such chemical nervous systems, there were no synapses yet and cellular patterns of excitation propagated by the release of secreted signalling molecules that influenced the activity of target cells expressing specific receptors. These signalling molecules may have initially been small molecules (e.g. glutamate, GABA, NO), but small peptides rapidly took over as the most significant paracrine signals. Peptides signalled environmental or internal states and enabled the coordination of effector activity and physiology in multicellular animal bodies. Paracrine signalling made chemical nervous systems diffusion limited suggesting that they could only have worked efficiently in small organisms. To overcome the limitations of diffusion, peptidergic cells evolved cellular projections, the precursors to axons, to increase the available surface for secretion. Synapses may have first evolved to link cells expressing the same peptides into neuronal nets allowing coordinated release of peptides through synchronisation. As animals grew bigger, synaptic signalling started to dominate and spread to the control of effectors. The evolution of circulatory systems in stem Bilateria enabled the rapid body-wide transport of peptides from neurohaemal release sites, overcoming the diffusion barrier. In parallel, peptidergic systems underwent explosive radiation. Complex peptidergic signalling networks still occur in every nervous system and modulate every circuit. These chemical networks form several hidden layers in the multilayer connectome of the brain where synaptic connectivity represents only one of many layers. 
(a)

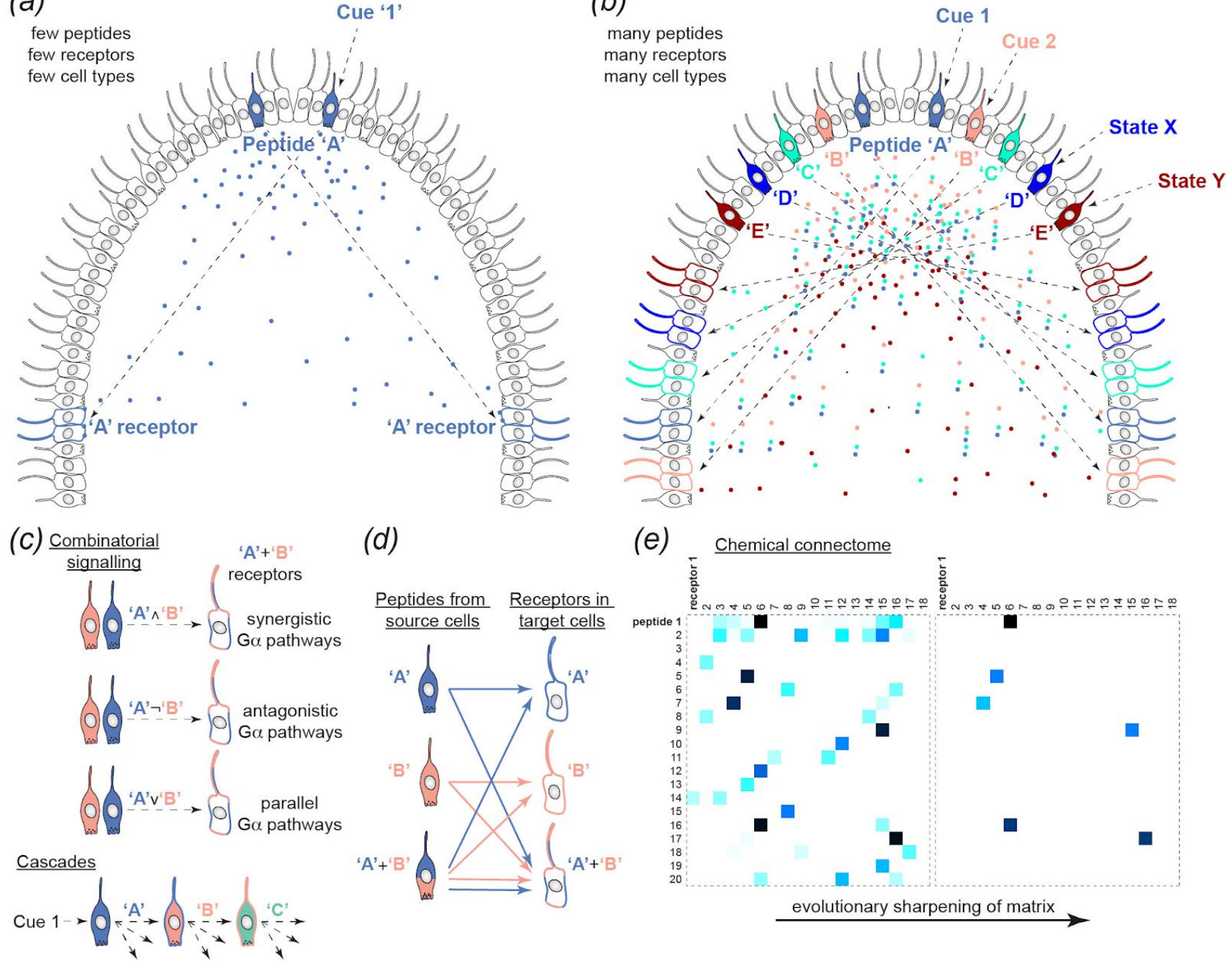

(b)

(e)

Figure 1. Wiring of complex networks in pre-nervous systems

(a) A hypothetical early animal with a ciliated epithelium with interspersed locomotor and sensory cells. One cell type expresses a signaling peptide that is released upon an external cue. The peptide signals to another cell type expressing a specific receptor for the peptide. (b) Through the diversification of cell types, signaling peptides and their receptors, an organism with more complex chemical wiring evolves. Note that peptides can not only be regulated by external cues but also by internal states (e.g. circadian rhythm, hunger). The effector systems could also include contractile cells. (c) If combinatorial signalling is possible, the chemical networks can encode state/cue combinations. This requires synergistic or antagonistic intracellular pathways (through Ga proteins for GPCRs). (d) With two peptides and two receptors it is possible to have eight signalling links with potentially different signalling outcomes. (e) The chemical connectome represents the matrix of ligand-receptor coupling but also the cellular coupling through these signalling pairs. Following gene duplications, the chemical matrix also evolves, e.g. through increasing specificity.

\section{B. Small peptides as the most successful neuronal signalling molecules}

Signalling neuropeptide-like molecules feature prominently in the chemical brain hypothesis. Their diversity and phylogenetic ancestry makes them the most likely molecules to have wired chemical networks in early animals. Neuropeptides are highly diverse and are present in all major clades of animals, with the exception of sponges [21-27]. Other signalling molecules could also have had an early origin in animal cell-cell communication, including GABA [28], glutamate, monoamines and nitric oxide (NO), a gaseous paracrine signalling molecule. NO signalling is present in sponges [28], placozoans [29], cnidarians [30], ctenophores [31] and bilaterians [32]. However, since NO chemistry lacks variation, this system could not have diversified into multiple related signalling molecules. Monoamines (serotonin, dopamine, noradrenaline, octopamine etc.) are very important 
in bilaterian nervous systems, but likely only diversified in the bilaterian stem group [33]. Their pre-bilaterian origins and functions are unclear.

By analogy with ecology, one can evaluate the success of a class of molecules as one can evaluate the success of a phylogenetic clade: by species richness and percent cover (e.g. [34]). According to these measures, neuropeptides are the most successful signalling molecules. They outnumber classical neurotransmitters by at least an order of magnitude in most nervous systems [26,35-41]. In terms of cover, neuropeptides collectively also rival classical neurotransmitters as they occur in most if not all neurons, often co-occurring with small transmitters [42,43]. Even in the mammalian neocortex - the epitome of a synaptically connected structure - almost all neurons express one or more neuropeptides and neuropeptide receptors [44].

Why did peptide signalling molecules attain such high diversity in nervous systems? Why were peptides favored in evolution over small molecules (e.g. NO, GABA) or globular proteins to wire chemical cellular networks? To address this question, we can compare these different classes of molecules in terms of their cost to the cell, their potential for evolutionary diversification, their diffusibility, stability and other measures (Table 1).

In terms of costs to the cell, short peptides are cheaper than long globular proteins. Several similar small peptides (even over 30) can also be produced by the cleavage of one precursor. In terms of diffusivity, small peptides and small molecules are generally more diffusive than globular proteins. The diffusion coefficient $D$ of a molecule is proportional to its molecular mass as $D \sim \mathrm{M}^{-0.3}[45,46]$. For example, the $D$ of bovine serum albumin $(M=65 \mathrm{kD})$ is $\sim 0.05 \times 10^{-5} \mathrm{~cm}^{2} / \mathrm{s}$. For the nonapeptide oxytocin ( $\mathrm{M}=1 \mathrm{kD}$ ), the $D$ is $~ 0.43 \times 10^{-5} \mathrm{~cm}^{2} / \mathrm{s}$ [47]. For nitric oxide ( $\mathrm{M}=30$ dalton), $D$ is $2.60 \times 10^{-5}$ $\mathrm{cm}^{2} / \mathrm{s}$ [48]. Figure 2 shows the relationship between molecular weight and diffusivity. Peptides clearly outperform proteins in their diffusibility, providing an advantage of faster spreading in paracrine signalling.

(a)

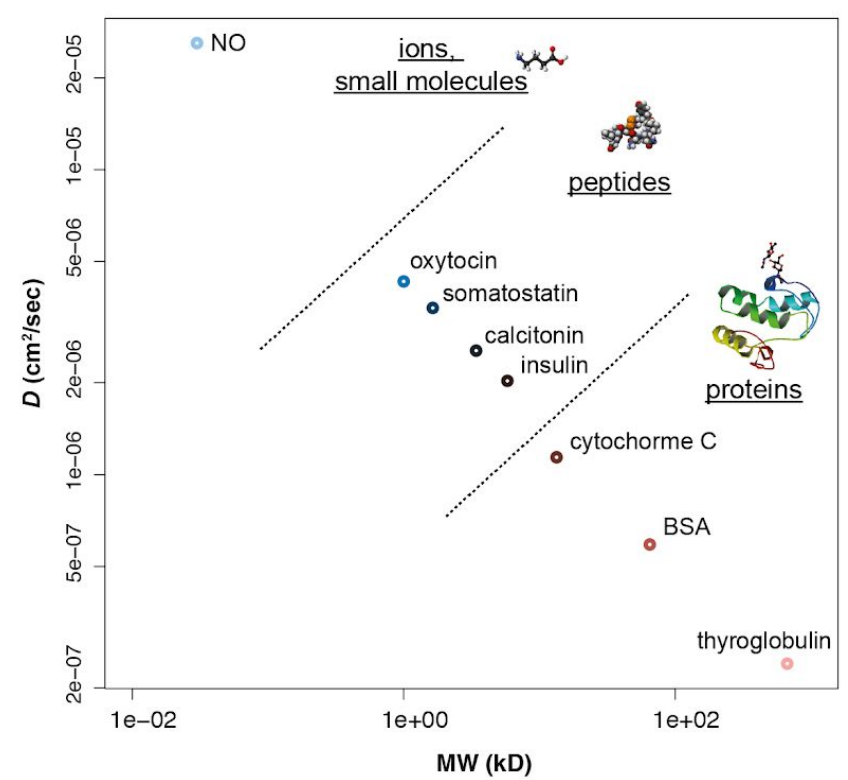

(b)

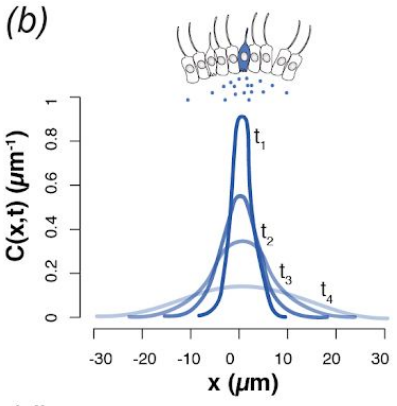

(d)

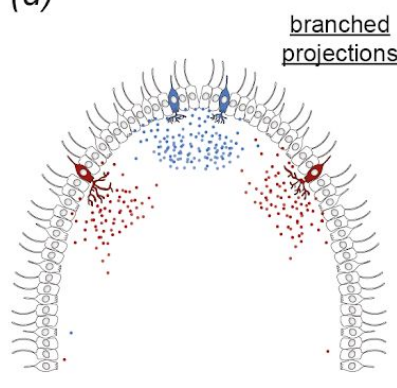

(c)

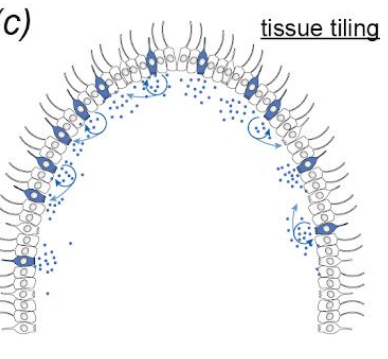

(e)

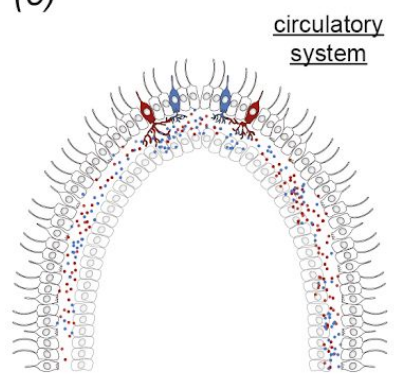

Figure 2. Diffusion of macromolecules and the diffusion limitation in chemical brains.

(a) Relationship of molecular weight and diffusion coefficient. Examples of proteins, neuropeptides and a small molecule (nitric oxide), compared for their molecular weight (MW) in kilodaltons and diffusion coefficient $(D)$, log-log scale. See main text for references. (b) Evolution of the concentration gradient by diffusion of signalling molecules after a local release event. The curves are only illustrations, based on the theory of diffusion, after [49]. (c) Tiling an epithelium with cells of the same type releasing the same peptide under the same conditions allows tissue-wide signalling. Autocrine signalling can allow spread and amplification. (d) Branched projections filled with dense core vesicles increase the membrane area 
available for secretion allowing the release of more peptides per event. (e) Fluid-filled spaces can speed the spread of signaling molecules, especially when aided by active circulation.

Next, we can compare the diversity of potential types evolution has access to within a class of molecules. Nitric oxide is monotypic and an evolutionary dead end. The diversity of small signalling molecules is theoretically endless, but their gradual diversification from one precursor (e.g. the origin of tyramine, octopamine, dopamine and noradrenaline from tyrosine) is limited. Furthermore, the evolution of a new version of a small molecule requires the evolution of a new enzymatic activity. This further limits the evolvability of small-molecule signalling pathways. In contrast, peptides have unlimited diversity with a 5 amino-acid-long form having $20^{5}$ possible variants, not considering modifications. Peptides can also easily diversify through the process of gene duplication and divergence or by intra-precursor divergence [50]. The evolution of receptors can follow, through coevolutionary diversification (duplication of both ligand and receptor, followed by the divergence of specificity), a general process in the evolution of peptide-receptor systems $[24,26,27]$.

Overall, if one considers synthesis costs, copy number, diffusibility, evolvability and potential diversity, small peptides are the clear winners and evolution did not overlook them.

There are also some limitations of peptidergic signalling. There are no dedicated reuptake or extracellular degradation pathways, unlike for classical neurotransmitters (e.g. acetylcholinesterase, SERT serotonin transporter). The possibilities to tune the extent and timing of extracellular signalling is thus more limited. Peptidergic signalling is also slower than synaptic signalling and plays out in the second rather than millisecond timescale. The main, early limitation, however, was probably diffusivity.

\begin{tabular}{|c|c|c|c|c|}
\hline $\begin{array}{l}\text { Type of } \\
\text { signalling } \\
\text { molecule }\end{array}$ & $\begin{array}{l}\text { Diffusion } \\
\text { coefficient }\end{array}$ & Synthesis & Evolvability & Diversity \\
\hline Ions, gases (NO) & $\sim 1-2 \times 10^{-5} \mathrm{~cm}^{2} / \mathrm{s}$ & $\begin{array}{l}\text { n.a. or by NO } \\
\text { synthase }\end{array}$ & none & limited \\
\hline Small molecules & $\sim 2 \times 10^{-5} \mathrm{~cm}^{2} / \mathrm{s}$ & $\begin{array}{l}\text { synthesis requires } \\
\text { several specific } \\
\text { enzymes }\end{array}$ & $\begin{array}{l}\text { limited, requires the } \\
\text { evolution of new enzymatic } \\
\text { activities, can co-evolve with } \\
\text { receptor }\end{array}$ & $\begin{array}{l}\text { theoretically unlimited, } \\
\text { limited by evolutionary } \\
\text { constraints }\end{array}$ \\
\hline Neuropeptides & $\begin{array}{l}\sim 0.2-0.5 \times 10^{-5} \\
\mathrm{~cm}^{2} / \mathrm{s}\end{array}$ & $\begin{array}{l}\text { on ribosomes, } \\
\text { followed by } \\
\text { proteolytic } \\
\text { cleavage and } \\
\text { modification }\end{array}$ & $\begin{array}{l}\text { highly evolvable, by } \\
\text { divergence within a } \\
\text { multi-copy precursor, by } \\
\text { gene duplication, often } \\
\text { co-evolves with receptor }\end{array}$ & $\begin{array}{l}\text { unlimited, } 20^{\mathrm{n}} \text {, where } \mathrm{n} \text { is } \\
\text { sequence length }\end{array}$ \\
\hline $\begin{array}{l}\text { Globular } \\
\text { proteins }\end{array}$ & $\begin{array}{l}\sim 0.02-0.1 \times 10^{-5} \\
\mathrm{~cm}^{2} / \mathrm{s}\end{array}$ & on ribosomes & $\begin{array}{l}\text { highly evolvable, by gene } \\
\text { duplication and divergence }\end{array}$ & $\begin{array}{l}\text { unlimited, } 20^{\mathrm{n}} \text {, where } \mathrm{n} \text { is } \\
\text { sequence length }\end{array}$ \\
\hline
\end{tabular}

Table 1. Characteristics of various classes of neuronal signalling molecules.

See main text for references.

\section{Peptidergic brains are diffusion limited}

Peptidergic brains are limited by diffusion. If, following activation, a cell releases a unit amount of signalling peptide, the peptide will diffuse with the characteristic diffusion constant in the intercellular space and its concentration will decay exponentially from the source and this curve will flatten with 
time (Figure 2b). Depending on the initial concentration and peptide-receptor affinity $\left(\mathrm{EC}_{50}\right.$ is often in the low nanomolar range for neuropeptide-GPCR activation), a peptidergic cell will only be able to signal to other cells within a given distance and its ability to reach more distant cells will decay exponentially.

There are at least three ways to overcome this diffusion barrier and to deliver signals to every cell in a tissue or across the entire organism. The first solution is to tile a surface (e.g. an epithelium) with several peptidergic cells of the same type (Figure 2c). We can see this for example in placozoans and the gonad epithelium of the jellyfish Clytia [22,51]. The placozoan Trichoplax adhaerens is tiled with a mosaic of peptidergic cells, most abundant at the perimeter of the disk-shaped body. In the Clytia gonad, cells expressing the neuropeptide maturation inducing hormone (MIH) tile the entire epithelium. From these examples, we can also estimate a peptidergic cell's signalling range as a few cell diameters or a few 10 s of $\mu \mathrm{ms}$. Autocrine signalling (the peptide stimulates its own release) can also lead to signal amplification and sustained and travelling activation. The second solution is to increase the concentration of secreted molecules by increasing the number of vesicles and the available membrane-surface for secretion. This can be achieved by the development of branched projections (Figure 2d). The third solution is to evolve a mechanism to deliver signalling molecules more rapidly across the body by active fluid circulation (Figure $2 \mathrm{e}$ ). I will discuss the evolutionary implications of the diffusion limit and the solutions to overcoming it in section two.

\section{Peptidergic signalling can wire complex cellular networks}

In nervous systems, there are two ways to build intercellular networks of signalling. In synaptic networks, cells or their processes connect to proximal cells via chemical or electric (gap junction) synapses. In peptidergic (or other paracrine) networks, 'sending' peptide-expressing cells connect to 'receiving' receptor-expressing cells. In such chemical networks, links are defined by ligand-receptor specificity and by the pattern of ligand and receptor expression. If there are many signalling peptides and receptors, it is possible to wire complex cellular networks by peptidergic signalling alone. The co-expression of multiple propeptides or multiple receptors in the same cell allows the further, combinatorial diversification of signalling (Figure 1). If two signalling peptides $\left(p e p_{1}\right.$ and $p_{e} p_{2}$ ) are released by the same cell, these could act on three different types of target cells, one expressing a receptor for $p p_{1}$, one for $p p_{2}$, and one for both. With two peptides and two receptors, it is possible to wire a network with 8 possible connections, each linking a different subset of cells and with potentially different signalling consequences (Figure 1d). If the second messenger cascades of the receptors are different and act synergistically or antagonistically, this could lead to multiple different signalling outcomes (Figure 1c). The system can thus have multiple states of activity which could encode several external or internal states.

Complex paracrine networks wired by neuropeptide and monoamine signalling indeed exist and have been mapped in several bilaterian nervous systems, including Caenorhabditis elegans, a nematode [52], Platynereis dumerilii, an annelid [53], Drosophila melanogaster, an arthropod [54], and Mus musculus, a vertebrate [44].

The high diversity and cell-type-specific expression of neuropeptides in placozoans, cnidarians and ctenophores $[23,39,55,56]$ also suggests the presence of specific cell-to-cell signalling and complex peptide-wired cellular networks in these organisms. In the placozoan Trichoplax, for example, there is a highly cell-type-specific proneuropeptide expression with 15 odd proneuropeptides each expressed in distinct cells, as shown by co-immunolabelling [22] and single-cell transcriptomics [57]. The evolution of cell-type-specific expression of peptides and receptors necessitates a unique and heritable gene regulatory landscape for each cell type. The diversification of chemical networks thus required not only the diversification of peptides and their receptors, but the diversification of cell types expressing unique combinations of them [58]. The two could have been strongly coupled in a 
sense that a new cell type (e.g. following sensory diversification) had to distinguish itself by a new chemical signature (i.e. a peptide mix). The tight specificity link between neuronal cell types and neuropeptides seems to be a general principle. In the mouse neocortex, neuropeptides and their receptors are "exceptionally potent neuron-type markers" [44]. Similar observations were made in the larval Platynereis brain based on single-cell RNAseq data [53]. Neuropeptides seem to be among the most specific and most highly-expressed neuronal markers across animals. This suggests that each neuron type has a specific peptidergic fingerprint. Upon activation, this fingerprint reveals the identity of the cell to its neighbours by paracrine signaling. The chemical brain hypothesis states that this and not the language of synapses is the first language proto-neurons used.

\section{Peptidergic signalling and scenarios for nervous system origins}

In this section, I discuss cellular transition scenarios for the origins of nervous systems, in light of the principles of paracrine signalling outlined above. I first review the evidence for the possible ciliary origins of neuropeptide signalling. I then discuss cases of neurosecretory signalling in cnidarians, placozoans and sponges. This is followed by a proposal for an elementary combinatorics of infraneuronal systems which helps to focus the discussion about when and in which order neuronal subsystems could have appeared and evolved into brains. Finally, I turn to the origin of neuronal processes, synaptically connected networks and neurohaemal organs.

\section{A. Ciliary origins of neuropeptide signalling}

How did neuropeptidergic signalling originate in animal evolution? What were its precursors and potential initial functions? Recent work from the laboratory of Betty Eipper has provided fascinating insights into this question. In 2016, the Eipper lab reported the presence of the peptidylglycine a-amidating monooxygenase (PAM) enzyme in the green alga Chlamydomonas reinhardtii [59]. PAM is involved in the $\alpha$-amidation of neuropeptides in animal brains and its presence in a green alga was surprising. An earlier bioinformatic study showed that PAM occurs in all animals and also outside animals in some protist lineages, and its origin thus predates nervous systems [60].

The Eipper team found that PAM localises to the cilia of Chlamydomonas. In subsequent work, they showed that PAM is required for the formation of cilia in Chlamydomonas [61]. In animals, the prime substrate of PAM are the cleaved, maturing neuropeptides. What could the enzyme modify in the alga? A mass-spectrometry screen revealed the identity of one of PAM's substrates in

Chlamydomonas as a chemoattractant peptide released on ciliary ectosomes that attracts gametes of the minus mating type [62]. This beautiful work shows the unexpected deep evolutionary ancestry of the machinery to produce amidated peptides and shows that the products of this machinery in a green alga are also involved in cell to cell signalling.

Comparative studies also suggest a widespread and ancient evolutionary connection of GPCR signalling to cilia. A proteomic analysis of cilia in the sea anemone Nematostella vectensis and the sea urchin Strongylocentrotus purpuratus identified several GPCRs and GPCR signalling components localised to the cilium [63]. Several neuropeptide GPCRs also localise to primary cilia in mammals [64].

These findings suggest a scenario whereby a signalling machinery involved in ciliary communication in protistan ancestors was recruited during animal evolution for the processing of signalling neuropeptides involved in intercellular communication. The secretion of bioactive amidated peptides in ciliary ectosomes emerges as the most likely cellular mechanism from which metazoan neuropeptide signalling evolved. Early on, secretion may have been apical and the amidated 
peptide products of PAM may have acted on GPCRs expressed on the cilia of receiving cells. The secretory machinery was later redirected to the nascent processes of the proto-neurosecretory cells.

\section{B. Sensory-neurosecretory cell types at the origin of nervous systems}

In what cellular and tissue context could have early peptidergic signalling operated? The studies of peptidergic systems in non-bilaterians can inform our thinking about early peptidergic networks. A particularly well-studied example is presented by light-sensory peptidergic cells in the hydrozoan Clytia hemispaerica. These sensory-neurosecreotry cells regulate the light-induced spawning of the Clytia jellyfish. The cells tile the gonad epithelium and express an opsin (a G-protein coupled receptor that together with retinal forms a photopigment) and a neuropeptide involved in oocyte maturation (maturation inducing hormone, $\mathrm{MIH}$ ) [65]. An increase in ambient light (at dawn in a natural setting) leads to the release of $\mathrm{MIH}$, a process that is defective in opsin mutant jellyfish [51]. The peptide activates a GPCR receptor (the MIH receptor) expressed in the oocyte to trigger spawning [66].

Neuropeptide-secreting cells with putative sensory functions have also been described in placozoans. Here, several distinct neuropeptide-like molecules, expressed in distinct cell types, can induce dramatic behavioural changes when added to the animals $[22,67]$. The behaviours include crinkling, rotation or flattening. Some of the peptide-expressing cells have a sensory morphology with a cilium [68]. It is not known which sensory cues may trigger peptide release, but some cues such as UV light trigger behaviours similar to the behaviours induced by some peptides [69]. This suggests that sensory cues could trigger the release of specific peptides from distinct cell types, eliciting coordinated behaviours.

Some sponges may also have sensory-neuroendocrine cells linking environmental cues to behaviour or developmental processes. Larvae of the demosponge Amphimedon queenslandica have different populations of flasked-shaped sensory cells that respond to settlement cues by calcium signalling [70], and release nitric oxide to regulate larval metamorphosis [71]. Although no neuropeptide-like molecule has been found in sponges, NO also represents a paracrine, diffusible molecule and the cells can be considered sensory-neuroendocrine.

\section{Elementary combinatorics of infraneuronal systems}

How did paracrine cellular networks evolve into synaptically connected nerve nets? When and why did projections and synapses appear and in what order? To explore this, I define an elementary combinatorics of infraneuronal systems for the origin of nervous systems, analogous to Szathmáry and colleagues' elementary combinatorics of infrabiological systems for the origin of life [72]. An infraneuronal system is defined as a necessary but not sufficient character of a structure that we would without doubt consider a nervous system. These infraneuronal systems include i) cellular excitability, ii) synaptic cell-to-cell signalling, iii) cellular projections, and iv) volumetric cell-to-cell signalling. Out of these four systems, cellular excitability through ion channels, pumps and receptors is the oldest and evolved in single celled organisms ([73] and Wan \& Jekely, this issue). The various combinations of the three other characters define three possible pathways to a full-fledged nervous system (Figure 3). As intermediates, we could imagine a nervous system with synapses+projections, volume transmission+projections, or synapses+volume transmission but no projections.

The chemical brain hypothesis proposes the early origin of neurosecretion, followed by the later evolution of projections and synapses. Below, I examine what could have favoured in an organism with neurosecretory cells the origin of projections and synapses. 


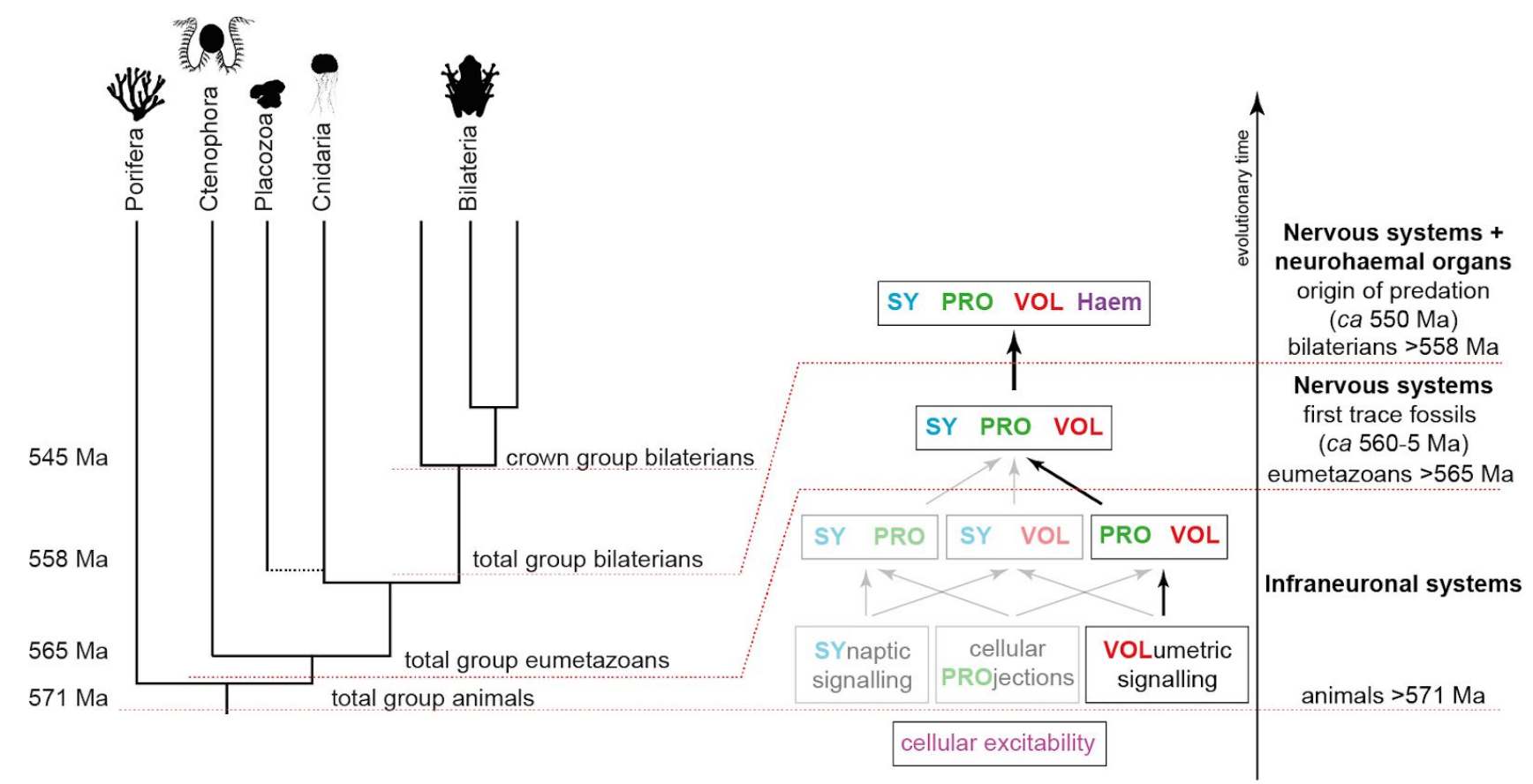

Figure 3. Elementary combinatorics of infraneuronal systems and the path suggested by the chemical brain hypothesis. Total group animals appeared shortly before $571 \mathrm{Ma}$, as suggested by the fossil record [74], and inherited the property of cellular excitability from their protist ancestors. Some aspects of advanced nervous systems appeared before eumetazoans, including volumetric signalling and possibly cellular projections involved in signalling. Total group eumetazoans appeared somewhat before 565 Ma with nervous systems combining synaptic transmission, projections and volume transmission appearing in the stem lineage or independently in ctenophores and cnidarians+bilaterians. The first trace fossils date to around the same time [75]. With total group bilaterians, neurohaemal organs and brains started to evolve [76], around $558 \mathrm{Ma}$. This period experienced the great neuropeptide explosion and was followed by the origin of predation (ca $550 \mathrm{Ma}$ ) [3] and the Cambrian explosion. Images are from PhyloPic.

\section{Origin of neuronal projections}

Why did neuronal projections first evolve? In a synaptically connected nervous system, the evolution of neuronal projections would allow long-range communication. Projections could either connect sensors to effectors [8,9] or contribute to the large-scale coordination of excitable tissue [7]. A computational model by de Wiljes and colleagues found that adding short projections that provide random connectivity can increase the coordination of activity patterns in larger tissues [7]. The chemical brain hypothesis offers an alternative explanation. In a peptide-secreting cell, branched cellular elongations containing secretory vesicles could increase the total membrane surface available for secretion. A cell with more projections filled with dense-core vesicles could secrete larger doses of peptides per excitation event, widening its range of signalling (Figure 2d). Neurosecretory cells can indeed have highly branched axonal morphologies and the branching neurites can contain many dense cored vesicles over their entire length. Figure 4 compares the morphology of sensory-neurosecretory neurons and non-neurosecretory sensory neurons in the brain of larval Platynereis dumerilii [53]. Comparing the number of branch points or individual neurons' Scholl value (a Scholl analysis scores how many times a neuron's branches cross concentric circles of increasing radii centered on the soma) show that sensory-neurosecretory neurons are highly branched, more than other types of sensory neurons. Since many of the sensory-neurosecretory neurons lack classical synapses in Platynereis [53], their highly branched morphology reflects the need to maximise release surface.

Cellular projections could evolve to uniformly cover an area in the tissue, to ensure that similar levels of signaling peptides reach all target cells simultaneously. In the gonad ectoderm of the jellyfish Clytia, the MIH-expressing light-sensory cells have branched elongations that uniformly 
cover the tissue (Figure 4d). The elongations are filled with neuropeptide-containing vesicles [51](Figure 4d). The tiling of the tissue together with the projections likely ensure a uniform release of $\mathrm{MIH}$ following a dark-light transition to uniformly stimulate the target cells, the maturing oocytes expressing the MIH receptor [66].

(a)

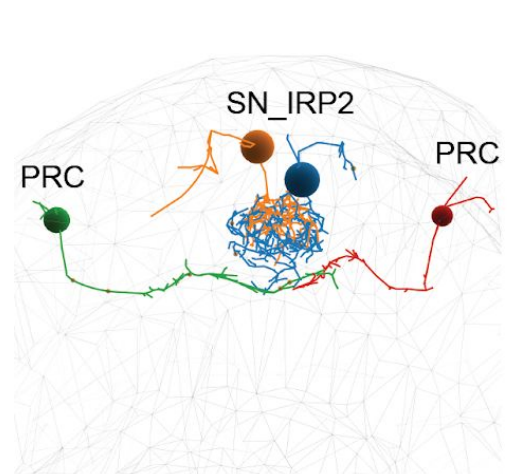

(b)

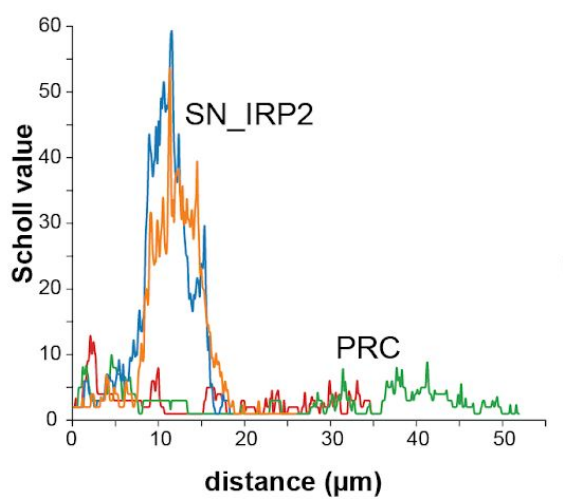

(e) (c)

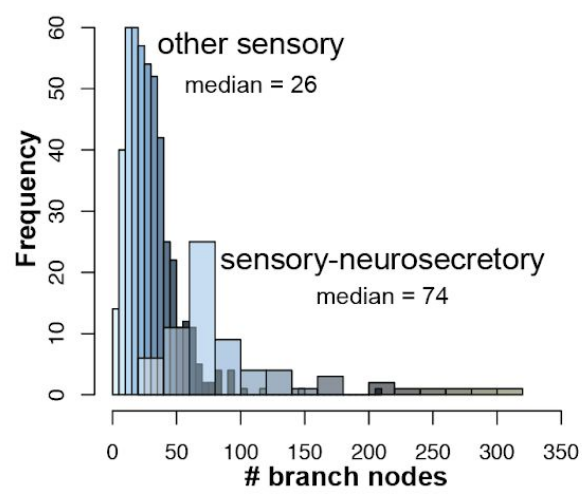

(f)

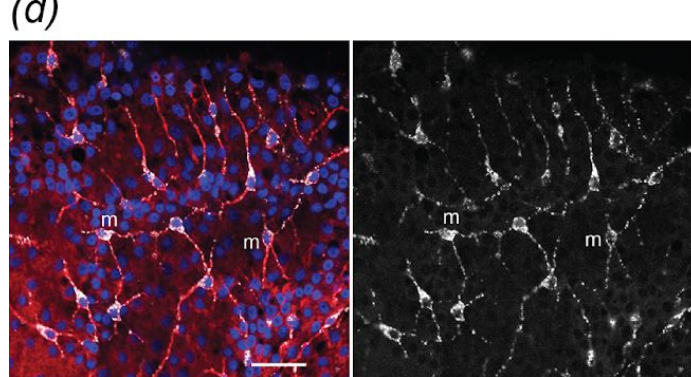

autocrine amplification

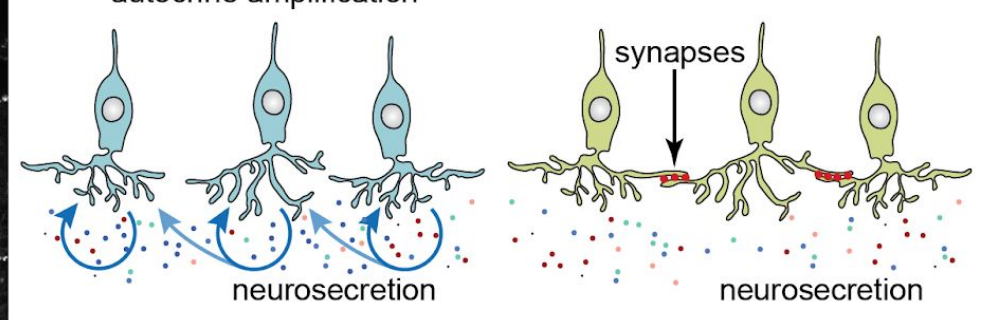

Figure 4. Neurite elongations in various neurosecretory cells.

(a) Morphology of two synaptic photoreceptor cells (PRC) and two sensory-neurosecretory cells (SN_IRP2) secreting an insulin-related peptide and other peptides in the $P$. dumerili larval brain. (b) Sholl analysis of the PRC and SN_IRP2 cells. A Sholl analysis scores the number of neuronal branches crossed by concentric circles of increasing radii centered in the soma of a neuron. (c) Histogram of the number of branch nodes in the $P$. dumerilii larval brain. The distribution is shown for sensory-neurosecretory cells and non-neurosecretory sensory cells. (d) Morphology of Clytia PRPamide-secreting cells. Confocal plane at the basal ectoderm level of the gonad. The anti-PRPamide staining labels peptidergic vesicles in the soma and processes of PRPamide cells $(\mathrm{m})$. The anti-a-tubulin staining (red) highlights the microtubule bundles in the basal processes. Scale bar $20 \mu \mathrm{m}$. (e) Schematic of autocrine amplification of neurosecretion. (f) Schematic of synaptic amplification of neurosecretion.

\section{E. Origin of synapses}

The chemical brain hypothesis also suggests a potential path for the origin of synaptic connections. It may be that the first synapses evolved to connect several sensory-neurosecretory cells of the same type into neuronal nets. Synapses with activatory transmitters linking cells of the same type could have enabled synchronous activation, with coordinated pulses or travelling waves of activity. This could have ensured synchronised peptide release across the entire field of cells, contributing to a more robust effector response.

Such degree of organisation may characterise some neuronal nets in cnidarians. For example, in the Clytia gonad, the $\mathrm{MIH}$-expressing cells may be linked through synapses. This could be tested by serial EM or by transgenic synapse markers. We know little about the nature of neurotransmitters in ctenophores and cnidarians and testing this scenario will require more research in this area. In 
Hydra, there are non-overlapping neuronal nets with distinct activity profiles [77]. What are the transmitters synchronising the propagating waves of activity in these nets? What are the transmitters released to the effectors? RFamide peptides In Hydra can induce muscle contractions, acting through a large variety of peptide-gated channels (the Hydra $\mathrm{Na}+$ channels or HyNaCs) expressed in epitheliomuscular cells and potentially involved in neuromuscular transmission [78]. From their function in synchronising peptidergic networks, synapses may have spread into other cellular contexts. Due to their more targeted, millisecond scale signalling eliciting spikining responses they started to dominate nervous system dynamics. This could have happened between 560-550 Ma as trace fossils started to diversify and animal-on-animal predation first appeared [3]. This also coincided with more complex, larger, and folded bodies (triploblasts) that presented a challenge for diffusion-limited paracrine signalling. One may think that this led to the demise of peptidergic networks. But this did not happen.

\section{F. Origin of neurohaemal organs and the end-Ediacaran neuropeptide explosion}

Comparative genomics has shown that peptidergic signalling systems have undergone an explosive radiation in stem bilaterians. There are approximately 30 proneuropeptide families and their receptors conserved across major bilaterian clades $[24,26,27,38,79]$. In contrast, few families trace back to the cnidarian-bilaterian common ancestor (RFamide, VWamide, PRXamide, insulin-like peptides, eclosion hormone (EH), bursicon, trunk [66,80-82]). These in general show a one-to-many relationship to bilaterian peptide and receptor families. For example, the receptor of the Clytia maturation-inducing hormone (MIHR) is sister to a bilaterian clade containing receptors for luqin, NPF, QRFP, tachykinin, FMRFa and NPY peptides [66]. Other cnidarian GPCRs show similar one-to-many or many-to-many relationship to bilaterian receptors $[38,66]$.

Why did peptidergic systems diversify in stem bilaterians that already had the ability for fast synaptic signalling? If we look at the distribution of neuropeptides in bilaterian brains, we always find the highest diversity and concentration in anterior neurosecretory-neurohaemal organs where brain peptides are directly released into the hemolymph (e.g. centipedes [83], annelids [53], vertebrates [84]).

Neurohaemal organs where neurosecretory endings are in close contact with blood vessels have been described in many animals [76,85-87] including annelids (infracerebral complex)[88,89], mollusks [90](e.g. the neurosecretory system of the vena cava in Octopus)[91], insects (pars intercerebralis - corpus cardiacum - corpus allatum system), crustaceans (X-organ and other organs) [87,92], millipedes [93,94], nemerteans [95], tunicates [86], cephalochordates [96], and vertebrates (the various circumventricular organs) [86].

The final postulate of the chemical brain hypothesis is that the evolution of circulation and neurohaemal organs released the constraints imposed on peptidergic signalling by diffusion. Hemocoelar circulation coupled to the release of peptides at a neurohaemal site ensured the rapid spread of peptides across the body.

Could it be that circulatory systems actually evolved for the transport of neuropeptides and not for the transport and exchange of gases and nutrients? Animals smaller than August Krogh's critical dimension of approximately $1 \mathrm{~mm}$ can rely on diffusion and skin breathing alone for respiration. Bilaterians in this size range can already have a hemocoel and active circulation, as found for example in the small interstitial annelid Dimorphilus (previously Dinophilus) gyrociliatus [97]. If gas exchange is not diffusion limited in an organism of this size, why does it have circulation? Could the reason be to ensure that signalling peptides reach target cells across the body to coordinate whole-body actions and physiology? There are many peptides expressed in the brain D. gyrociliatus 
[98]. A neurohaemal organ has not been described but such organs have been studied in other annelids $[88,89,99]$.

Neurohaemal organs thus allowed concentrated peptide release, setting free the peptides to travel in the 'Loop' train of the circulating haemolymph, defying diffusion. This new route to spread may have facilitated diversification, allowing peptides to remain on centre stage in bilaterian brains.

\section{Testing the hypothesis}

The chemical brain hypothesis discusses how elementary nervous systems may have functioned and evolved. Some of the ideas may apply to extant nervous systems, in particular to non-bilaterians and larval bilaterians which potentially retained a richer mosaic of ancestral characters. Evolutionary hypotheses and transition analyses try to account for past events but also aid thinking and hopefully stimulate future work. Future results based on predictions of the hypothesis can in turn test the hypothesis. I list some questions that were inspired by writing this piece and that could be tested experimentally.

What is the function of $\alpha$-amidation in choanoflagellates and sponges? Are there amidated products involved in intercellular signalling? Are these in the gametes or multicellular stages? A better understanding of PAM function and related molecules (e.g. its copper transporter) could illuminate this.

Why do placozoan peptidergic cells have no projections? Fibre cells do have projections, thus the organism has the ability to grow them [68]. Could this be that at the scale of Trichoplax, diffusion is not limiting? Is the fluid-filled lumen between the dorsal and ventral epithelia a mediator of peptide signalling? Some of this could be tested by fluorescent tracers (e.g. dextrans, peptides) and live imaging.

Is there combinatorial and autocrine peptide signalling in placozoans and cnidarians? Are there cells coexpressing >1 peptide receptors? Could some of the ciliary-localised GPCRs in Nematosella be peptide receptors? How complex are the peptidergic networks and do they contain peptide cascades? Addressing these questions will first require the identification and cellular mapping of such receptors.

What is the relationship between peptidergic and classical transmitter action in cnidarians? Are peptides or classical transmitters the main transmitters on effector cells? Which transmitters synchronise each of the non-overlapping neuronal networks in cnidarians [77]? Are there synapses between the MIH-expressing cells in Clytia? We will need to learn more about synapses and transmitters in cnidarians. New transgenic lines [100] and serial EM could help to address this. What is the primary function of circulation in small aquatic bilaterians? Is it the transport of oxygen, nutrients or hormones? Can we test this by optogenetically inhibiting the heart in a small interstitial animal? Would they suffocate or break down hormonally first?

And I haven't even mentioned ctenophores... [20,21,31,55,68]

\section{Envoi}

Is the chemical brain hypothesis a good hypothesis about the origin of nervous systems? A hypothesis is good and useful if it is testable and stimulates fresh thinking, new questions or experiments. As Raymond Goldstein put it, "If [mathematical] theories are crafted the right way they have utility even if proven wrong, sometimes especially if proven wrong!" [49]. The same is true for evolutionary hypotheses. Writing this piece suggested new questions and experiments and hopefully will also stimulate the reader. 


\section{References}

1. Mackie GO. 1970 Neuroid conduction and the evolution of conducting tissues. Q. Rev. Biol. 45, 319-332.

2. Kristan WB Jr. 2016 Early evolution of neurons. Curr. Biol. 26, R949-R954.

3. Monk T, Paulin MG. 2014 Predation and the origin of neurones. Brain Behav. Evol. 84, 246-261.

4. Arendt D. 2008 The evolution of cell types in animals: emerging principles from molecular studies. Nature Reviews Genetics. 9, 868-882. (doi:10.1038/nrg2416)

5. Sinigaglia C, Busengdal H, Leclère L, Technau U, Rentzsch F. 2013 The Bilaterian Head Patterning Gene six3/6 Controls Aboral Domain Development in a Cnidarian. PLoS Biology. 11, e1001488. (doi:10.1371/journal.pbio.1001488)

6. Kelava I, Rentzsch F, Technau U. 2015 Evolution of eumetazoan nervous systems: insights from cnidarians. Philos. Trans. R. Soc. Lond. B Biol. Sci. 370. (doi:10.1098/rstb.2015.0065)

7. Wiljes $\mathrm{OO}$ de, de Wiljes OO, van Elburg RAJ, Keijzer FA. 2017 Modelling the effects of short and random proto-neural elongations. Journal of The Royal Society Interface. 14, 20170399. (doi:10.1098/rsif.2017.0399)

8. Jékely G. 2011 Origin and early evolution of neural circuits for the control of ciliary locomotion. Proc. Biol. Sci. 278, 914-922.

9. Braitenberg V. 1986 Vehicles: Experiments in Synthetic Psychology. MIT Press.

10. Keijzer F, van Duijn M, Lyon P. 2013 What nervous systems do: early evolution, input-output, and the skin brain thesis. Adaptive Behavior. 21, 67-85. (doi:10.1177/1059712312465330)

11. Jekely G, Keijzer F, Smith PG. In press. An Option Space for Early Neural Evolution. (doi:10.1101/027425)

12. Eipper BA, Stoffers DA, Mains RE. 1992 The Biosynthesis of Neuropeptides: Peptide alpha-Amidation. Annual Review of Neuroscience. 15, 57-85.

(doi:10.1146/annurev.ne.15.030192.000421)

13. Steuer Costa W, Yu S-C, Liewald JF, Gottschalk A. 2017 Fast cAMP Modulation of Neurotransmission via Neuropeptide Signals and Vesicle Loading. Curr. Biol. 27, 495-507.

14. Wang Y et al. 2017 Ligand- and voltage-gated Ca channels differentially regulate the mode of vesicular neuropeptide release in mammalian sensory neurons. Sci. Signal. 10.

(doi:10.1126/scisignal.aal1683)

15. Renden R, Berwin B, Davis W, Ann K, Chin CT, Kreber R, Ganetzky B, Martin TF, Broadie K. 2001 Drosophila CAPS is an essential gene that regulates dense-core vesicle release and synaptic vesicle fusion. Neuron $31,421-437$.

16. Walch-Solimena C, Takei K, Marek KL, Midyett K, Südhof TC, De Camilli P, Jahn R. 1993 Synaptotagmin: a membrane constituent of neuropeptide-containing large dense-core vesicles. J. Neurosci. 13, 3895-3903.

17. Speese S, Petrie M, Schuske K, Ailion M, Ann K, Iwasaki K, Jorgensen EM, Martin TFJ. 2007 UNC-31 (CAPS) Is Required for Dense-Core Vesicle But Not Synaptic Vesicle Exocytosis in 
Caenorhabditis elegans. Journal of Neuroscience. 27, 6150-6162.

(doi:10.1523/jneurosci.1466-07.2007)

18. Paquin N, Murata Y, Froehlich A, Omura DT, Ailion M, Pender CL, Constantine-Paton M, Horvitz HR. 2016 The Conserved VPS-50 Protein Functions in Dense-Core Vesicle Maturation and Acidification and Controls Animal Behavior. Curr. Biol. 26, 862-871.

19. Mackie GO. 1990 The Elementary Nervous System Revisited. American Zoologist. 30, 907-920. (doi:10.1093/icb/30.4.907)

20. Moroz LL. 2009 On the independent origins of complex brains and neurons. Brain Behav. Evol. 74, 177-190.

21. Moroz LL, Kohn AB. 2015 Unbiased View of Synaptic and Neuronal Gene Complement in Ctenophores: Are There Pan-neuronal and Pan-synaptic Genes across Metazoa? Integr. Comp. Biol. 55, 1028-1049.

22. Varoqueaux F, Williams EA, Grandemange S, Truscello L, Kamm K, Schierwater B, Jékely G, Fasshauer D. 2018 High Cell Diversity and Complex Peptidergic Signaling Underlie Placozoan Behavior. Curr. Biol. 28, 3495-3501.e2.

23. Nikitin M. 2015 Bioinformatic prediction of Trichoplax adhaerens regulatory peptides. Gen. Comp. Endocrinol. 212, 145-155.

24. Jekely G. 2013 Global view of the evolution and diversity of metazoan neuropeptide signaling. Proceedings of the National Academy of Sciences. 110, 8702-8707. (doi:10.1073/pnas.1221833110)

25. Nielsen SKD, Koch TL, Hauser F, Garm A, Grimmelikhuijzen CJP. 2019 De novo transcriptome assembly of the cubomedusa Tripedalia cystophora, including the analysis of a set of genes involved in peptidergic neurotransmission. BMC Genomics 20, 175.

26. Elphick MR, Mirabeau O, Larhammar D. 2018 Evolution of neuropeptide signalling systems. J. Exp. Biol. 221. (doi:10.1242/jeb.151092)

27. Mirabeau O, Joly J-S. 2013 Molecular evolution of peptidergic signaling systems in bilaterians. Proc. Natl. Acad. Sci. U. S. A. 110, E2028-37.

28. Elliott GRD, Leys SP. 2010 Evidence for glutamate, GABA and NO in coordinating behaviour in the sponge, Ephydatia muelleri (Demospongiae, Spongillidae). J. Exp. Biol. 213, 2310-2321.

29. Moroz LL, Romanova DY, Nikitin MA, Sohn D, Kohn AB, Neveu E, Varoqueaux F, Fasshauer D. 2020 Nitric oxide (NO) signaling in Trichoplax and related species: Microchemical characterization and the lineage-specific diversification. Evolutionary Biology. , 109.

30. Cristino L, Guglielmotti V, Cotugno A, Musio C, Santillo S. 2008 Nitric oxide signaling pathways at neural level in invertebrates: functional implications in cnidarians. Brain Res. 1225, 17-25.

31. Moroz LL, Kohn AB. 2016 Independent origins of neurons and synapses: insights from ctenophores. Philos. Trans. R. Soc. Lond. B Biol. Sci. 371, 20150041.

32. Jacklet JW. 1997 Nitric oxide signaling in invertebrates. Invert. Neurosci. 3, 1-14.

33. Bauknecht P, Jékely G. 2017 Ancient coexistence of norepinephrine, tyramine, and octopamine signaling in bilaterians. BMC Biol. 15, 6 .

34. Rothwell GW. 1996 Pteridophytic evolution: an often underappreciated phytological success story. Review of Palaeobotany and Palynology. 90, 209-222. 
35. McVeigh P, Alexander-Bowman S, Veal E, Mousley A, Marks NJ, Maule AG. 2008 Neuropeptide-like protein diversity in phylum Nematoda. Int. J. Parasitol. 38, 1493-1503.

36. Conzelmann M, Williams EA, Krug K, Franz-Wachtel M, Macek B, Jékely G. 2013 The neuropeptide complement of the marine annelid Platynereis dumerilii. BMC Genomics 14, 906.

37. Fu Q, Kutz KK, Schmidt JJ, Hsu Y-WA, Messinger DI, Cain SD, de la Iglesia HO, Christie AE, Li L. 2005 Hormone complement of the Cancer productus sinus gland and pericardial organ: an anatomical and mass spectrometric investigation. J. Comp. Neurol. 493, 607-626.

38. Thiel D, Franz-Wachtel M, Aguilera F, Hejnol A. 2018 Xenacoelomorph Neuropeptidomes Reveal a Major Expansion of Neuropeptide Systems during Early Bilaterian Evolution. Molecular Biology and Evolution. 35, 2528-2543. (doi:10.1093/molbev/msy160)

39. Fujisawa T. 2008 Hydra peptide project 1993-2007. Dev. Growth Differ. 50 Suppl 1, S257-68.

40. Hewes RS. 2001 Neuropeptides and Neuropeptide Receptors in the Drosophila melanogaster Genome. Genome Research. 11, 1126-1142. (doi:10.1101/gr.169901)

41. Nathoo AN, Moeller RA, Westlund BA, Hart AC. 2001 Identification of neuropeptide-like protein gene families in Caenorhabditiselegans and other species. Proc. Natl. Acad. Sci. U. S. A. 98 , 14000-14005.

42. Lundberg JM, Hökfelt T. 1983 Coexistence of peptides and classical neurotransmitters. Trends in Neurosciences. 6, 325-333. (doi:10.1016/0166-2236(83)90149-2)

43. Snyder S. 1980 Brain peptides as neurotransmitters. Science. 209, 976-983. (doi:10.1126/science.6157191)

44. Smith SJ et al. 2019 Single-cell transcriptomic evidence for dense intracortical neuropeptide networks. Elife 8. (doi:10.7554/eLife.47889)

45. Krouglova T, Vercammen J, Engelborghs Y. 2004 Correct diffusion coefficients of proteins in fluorescence correlation spectroscopy. Application to tubulin oligomers induced by $\mathrm{Mg} 2+$ and Paclitaxel. Biophys. J. 87, 2635-2646.

46. Young ME, Carroad PA, Bell RL. 1980 Estimation of diffusion coefficients of proteins. Biotechnology and Bioengineering. 22, 947-955. (doi:10.1002/bit.260220504)

47. Hosoya O, Chono S, Saso Y, Juni K, Morimoto K, Seki T. 2004 Determination of diffusion coefficients of peptides and prediction of permeability through a porous membrane. J. Pharm. Pharmacol. 56, 1501-1507.

48. Cussler EL, Cussler EL. 1997 Diffusion: Mass Transfer in Fluid Systems. Cambridge University Press.

49. Goldstein RE. 2018 Are theoretical results 'Results'? eLife. 7. (doi:10.7554/elife.40018)

50. Schmidt A, Bauknecht P, Williams EA, Augustinowski K, Gründer S, Jékely G. 2018 Dual signaling of Wamide myoinhibitory peptides through a peptide-gated channel and a GPCR in Platynereis. FASEB J. 32, 5338-5349.

51. Artigas GQ, Lapébie P, Leclère L, Takeda N, Deguchi R, Jékely G, Momose T, Houliston E. 2018 A gonad-expressed opsin mediates light-induced spawning in the jellyfish Clytia. eLife. 7. (doi:10.7554/elife.29555) 
52. Bentley B, Branicky R, Barnes CL, Chew YL, Yemini E, Bullmore ET, Vértes PE, Schafer WR. 2016 The Multilayer Connectome of Caenorhabditis elegans. PLoS Comput. Biol. 12, e1005283.

53. Williams EA, Verasztó C, Jasek S, Conzelmann M, Shahidi R, Bauknecht P, Mirabeau O, Jékely G. 2017 Synaptic and peptidergic connectome of a neurosecretory center in the annelid brain. Elife 6. (doi:10.7554/eLife.26349)

54. Deng B et al. 2019 Chemoconnectomics: Mapping Chemical Transmission in Drosophila. Neuron 101, 876-893.e4.

55. Moroz LL et al. 2014 The ctenophore genome and the evolutionary origins of neural systems. Nature 510, 109-114.

56. Watanabe H, Fujisawa T, Holstein TW. 2009 Cnidarians and the evolutionary origin of the nervous system. Dev. Growth Differ. 51, 167-183.

57. Sebé-Pedrós A et al. 2018 Early metazoan cell type diversity and the evolution of multicellular gene regulation. Nat Ecol Evol 2, 1176-1188.

58. Arendt D et al. 2016 The origin and evolution of cell types. Nat. Rev. Genet. 17, 744-757.

59. Kumar D, Blaby-Haas CE, Merchant SS, Mains RE, King SM, Eipper BA. 2016 Early eukaryotic origins for cilia-associated bioactive peptide-amidating activity. J. Cell Sci. 129, 943-956.

60. Attenborough RMF, Hayward DC, Kitahara MV, Miller DJ, Ball EE. 2012 A 'neural' enzyme in nonbilaterian animals and algae: preneural origins for peptidylglycine $\alpha$-amidating monooxygenase. Mol. Biol. Evol. 29, 3095-3109.

61. Kumar D, Strenkert D, Patel-King RS, Leonard MT, Merchant SS, Mains RE, King SM, Eipper BA. 2017 A bioactive peptide amidating enzyme is required for ciliogenesis. Elife 6. (doi:10.7554/eLife.25728)

62. Luxmi R, Kumar D, Mains RE, King SM, Eipper BA. 2019 Cilia-based peptidergic signaling. PLoS Biol. 17, e3000566.

63. Sigg MA et al. 2017 Evolutionary Proteomics Uncovers Ancient Associations of Cilia with Signaling Pathways. Dev. Cell 43, 744-762.e11.

64. Hilgendorf KI, Johnson CT, Jackson PK. 2016 The primary cilium as a cellular receiver: organizing ciliary GPCR signaling. Curr. Opin. Cell Biol. 39, 84-92.

65. Takeda $\mathrm{N}$ et al. 2018 Identification of jellyfish neuropeptides that act directly as oocyte maturation-inducing hormones. Development 145. (doi:10.1242/dev.156786)

66. Quiroga Artigas $G$, Lapébie $P$, Leclère L, Bauknecht $P$, Uveira J, Chevalier $S$, Jékely $G$, Momose T, Houliston E. 2020 A G protein-coupled receptor mediates neuropeptide-induced oocyte maturation in the jellyfish Clytia. PLoS Biol. 18, e3000614.

67. Senatore A, Reese TS, Smith CL. 2017 Neuropeptidergic integration of behavior in , an animal without synapses. J. Exp. Biol. 220, 3381-3390.

68. Smith CL, Varoqueaux F, Kittelmann M, Azzam RN, Cooper B, Winters CA, Eitel M, Fasshauer D, Reese TS. 2014 Novel cell types, neurosecretory cells, and body plan of the early-diverging metazoan Trichoplax adhaerens. Curr. Biol. 24, 1565-1572.

69. Pearse VB. 1989 Growth and Behavior of Trichoplax adhaerens: First Record of the Phylum 
Placozoa in Hawaii.

70. Nakanishi N, Stoupin D, Degnan SM, Degnan BM. 2015 Sensory Flask Cells in Sponge Larvae Regulate Metamorphosis via Calcium Signaling. Integr. Comp. Biol. 55, 1018-1027.

71. Ueda N, Richards GS, Degnan BM, Kranz A, Adamska M, Croll RP, Degnan SM. 2016 An ancient role for nitric oxide in regulating the animal pelagobenthic life cycle: evidence from a marine sponge. Scientific Reports. 6. (doi:10.1038/srep37546)

72. Szathmáry E, Santos M, Fernando C. 2005 Evolutionary Potential and Requirements for Minimal Protocells. In Prebiotic Chemistry (ed P Walde), pp. 167-211. Berlin/Heidelberg: Springer-Verlag.

73. Brunet T, Arendt D. 2016 From damage response to action potentials: early evolution of neural and contractile modules in stem eukaryotes. Philos. Trans. R. Soc. Lond. B Biol. Sci. 371, 20150043.

74. Budd G, Mann RP. In press. Survival and selection biases in early animal evolution and a source of systematic overestimation in molecular clocks. (doi:10.31233/osf.io/j45yf)

75. Budd GE. 2015 Early animal evolution and the origins of nervous systems. Philosophical Transactions of the Royal Society B: Biological Sciences. 370, 20150037.

(doi:10.1098/rstb.2015.0037)

76. Tessmar-Raible K. 2007 The evolution of neurosecretory centers in bilaterian forebrains: insights from protostomes. Semin. Cell Dev. Biol. 18, 492-501.

77. Dupre C, Yuste R. 2017 Non-overlapping Neural Networks in Hydra vulgaris. Curr. Biol. 27, 1085-1097.

78. Assmann M, Kuhn A, Dürrnagel S, Holstein TW, Gründer S. 2014 The comprehensive analysis of $D E G / E N a C$ subunits in Hydra reveals a large variety of peptide-gated channels, potentially involved in neuromuscular transmission. BMC Biol. 12, 84.

79. Bauknecht P, Jékely G. 2015 Large-Scale Combinatorial Deorphanization of Platynereis Neuropeptide GPCRs. Cell Rep. 12, 684-693.

80. de Oliveira AL, Calcino A, Wanninger A. 2019 Ancient origins of arthropod moulting pathway components. Elife 8. (doi:10.7554/eLife.46113)

81. Conzelmann M, Williams EA, Tunaru S, Randel N, Shahidi R, Asadulina A, Berger J, Offermanns S, Jékely G. 2013 Conserved MIP receptor-ligand pair regulates Platynereis larval settlement. Proc. Natl. Acad. Sci. U. S. A. 110, 8224-8229.

82. Steinmetz P, Aman A, Kraus J, Technau U. 2017 Gut-like ectodermal tissue in a sea anemone challenges germ layer homology. Mechanisms of Development. 145, S111.

(doi:10.1016/j.mod.2017.04.295)

83. Hunnekuhl VS, Akam M. 2014 An anterior medial cell population with an apical-organ-like transcriptional profile that pioneers the central nervous system in the centipede Strigamia maritima. Dev. Biol. 396, 136-149.

84. Herget U, Wolf A, Wullimann MF, Ryu S. 2014 Molecular neuroanatomy and chemoarchitecture of the neurosecretory preoptic-hypothalamic area in zebrafish larvae. J. Comp. Neurol. 522, 1542-1564.

85. Golding DW. 1974 A survey of neuroendocrine phenomena in non-arthropod invertebrates. 
Biol. Rev. Camb. Philos. Soc. 49, 161-224.

86. Joly J-S, Osório J, Alunni A, Auger H, Kano S, Rétaux S. 2007 Windows of the brain: towards a developmental biology of circumventricular and other neurohemal organs. Semin. Cell Dev.

Biol. 18, 512-524.

87. Hartenstein V. 2006 The neuroendocrine system of invertebrates: a developmental and evolutionary perspective. J. Endocrinol. 190, 555-570.

88. Golding DW. 1967 The diversity of secretory neurones in the brain of nereis. Z. Zellforsch. Mikrosk. Anat. 82, 321-344.

89. Baskin DG. 1974 Further observations on the fine structure and development of the infracerebral complex ('infracerebral gland') of Nereis limnicola (Annelida, Polychaeta). Cell Tissue Res. 154, 519-531.

90. Simpson L, Bern HA, Nishioka RS. 1966 Survey of evidence for neurosecretion in gastropod molluscs. Am. Zool. 6, 123-138.

91. Martin R, Voigt KH. 1987 The neurosecretory system of the octopus vena cava: A neurohemal organ. Experientia. 43, 537-543. (doi:10.1007/bf02143582)

92. Keller R. 1992 Crustacean neuropeptides: structures, functions and comparative aspects. Experientia 48, 439-448.

93. Shukla GS, Tripathi SP. 1980 Neurosecretory System of Millipede Gonoplectus malayus (CARL.) (Myriapoda, Diplopoda). Deutsche Entomologische Zeitschrift (neue Folge). 27, 319-325. (doi:10.1002/mmnd.4810270411)

94. Warburg MR, Rosenberg M. 1983 Cerebral Neurosecretory Cells in the Millipede,Archispirostreptus syriacus, De Saussure (Diplopoda, Spirostreptiadae). Acta Zoologica. 64, 107-115. (doi:10.1111/j.1463-6395.1983.tb00788.x)

95. Bianchi S. 1969 On the neurosecretory system of Cerebratulus marginatus (Heteronemertini). Gen. Comp. Endocrinol. 12, 541-548.

96. Obermüller-Wilén H. 1979 A Neurosecretory System in the Brain of the Lancelet,Branchiostoma lanceolatum. Acta Zoologica. 60, 187-196. (doi:10.1111/j.1463-6395.1979.tb00611.x)

97. Bourne GH. 1980 Hearts and Heart-like Organs: Comparative anatomy and development.

98. Kerbl A, Conzelmann M, Jékely G, Worsaae K. 2017 High diversity in neuropeptide immunoreactivity patterns among three closely related species of Dinophilidae (Annelida). J. Comp. Neurol. 525, 3596-3635.

99. Golding DW. 1973 Neuroendocrine Phenomena in Aphroditid and Related Polychaetes. Acta Zoologica. 54, 101-120. (doi:10.1111/j.1463-6395.1973.tb00446.x)

100. Cole AG et al. 2020 Muscle cell type diversification facilitated by extensive gene duplications. Developmental Biology. , 1163. 